\title{
The Effects of Growth Hormone Treatment in Patients with Isolated Growth Hormone Deficiency on Hematological Parameters
}

\author{
(D) Derya Şengün ${ }^{1}$, (D) Atilla Çayır² \\ 1Private Çorlu Reyap Hospital, Clinic of Child Health and Diseases, Erzurum, Turkey \\ 2Erzurum Training and Research Hospital, Clinic of Pediatric Endocrinology, Erzurum, Turkey
}

Cite this article as: Şengün D, Çayır A. The Effects of Growth Hormone Treatment in Patients with Isolated Growth Hormone Deficiency on Hematological Parameters. Trends in Pediatrics 2021;2(4):165-169

\begin{abstract}
Objective: A small number of studies were reported regarding the direct and indirect effects of growth hormone (GH) and insulin-like growth factor-1 (IGF-1) especially on the erythrocyte series. The purpose of this study was to examine the effects of GH treatment (GHT) used in patients with isolated GH deficiency (IGHD) on hematological parameters.

Methods: The records of the patients who were diagnosed as having IGHD in our clinic and received GHT for at least two years between 2013 and 2019 were retrospectively examined. Height, height standard deviation scores (SDS), weight, weight SDS, IGF-1, annual growth rates, and changes in blood count parameters before and after the GHT were recorded. The statistical analyses were made using SPSS v.20 Package Program, and the significance level was accepted as $p<0.05$.

Results: A total of $37 \%(n=23)$ of the 62 patients that were included in the study were female, and $63 \%(n=39)$ were male. It was determined that the age of the patients was between 2-16 years at the time of diagnosis, and the median age at diagnosis was 10.8. After the GHT, a significant increase was detected in the distribution and volume of hemoglobin, hematocrit, and red sphere count $(\mathrm{p}<0.05)$. A statistically significant but clinically insignificant decrease was detected in the platelet count and there was an increase in the platelet volumes ( $p<0.001)$. A clinically significant decrease was detected in the number of white sphere, lymphocyte and neutrophil counts $(p<0.05)$.

Conclusion: It was determined that GHT had a stimulating effect on erythropoiesis in IGHD. It was also shown that GHT caused a number of changes on the platelet count, white sphere count, and the lymphocyte and neutrophil parameters, which were not clinically important. We believe that studies at in vitro and molecular level are needed to explain the effects of GHD and GHT on the hematopoietic system.
\end{abstract}

Keywords: Growth hormone, isolated growth hormone deficiency, growth hormone therapy, hematological parameters, child

\section{INTRODUCTION}

Growth hormone deficiency (GHD) is a significant cause of short stature, seen in approximately $1 / 4,000$ to $1 / 10,000$ of the patients. ${ }^{1,2}$ Isolated GHD (IGHD) can be defined as the deficiency of $\mathrm{GH}$ that is independent of other pituitary hormone deficiencies and the presence of an organic lesion. ${ }^{3}$ GHD can be either congenital or acquired, while the height and weight of patients at birth are in the normal range. The children with GHD are expected to have regular growth during the first six months, while the growth slows down later in life. A proportionally short height ensues and the weight increases relative to the height, leading to delayed bone age. ${ }^{2}$

Treatment of GHD involves the use of biosynthetic human growth hormone produced by recombinant gene technologies (rhGH). The

D. Şengün: 0000-0003-4772-731X

Address for Correspondence: Atilla Çayır

Erzurum Training and Research Hospital, Clinic of Pediatric Endocrinology, Erzurum, Turkey

E-mail: dratillacayir@gmail.com ORCID-ID: orcid.org/0000-0001-9776-555X

Received: 23.07.2021 Accepted: 08.11.2021 Publication date: 04.01.2022

${ }^{\circ}$ Copyright 2021 by the Aydın Pediatric Society / Trends in Pediatrics published by Galenos Publishing House.

Licenced by Creative Commons Attribution 4.0 International (CC BY) 
rhGH is safely used with very rare side effects. Growth hormone has been shown to have metabolic effects related to several systems besides its effects on height. Carbohydrate, fat, and protein metabolisms are adversely affected, body composition deteriorates, bone health is adversely affected, quality of life decreases, and cardiovascular morbidity increases in GHD. ${ }^{4,5}$

It is known that GH and insulin-like growth factor-1 (IGF-1) have effects on the hematopoietic system. GH and IGF-1 regulate hematopoiesis and cytokine production via bone marrow. $\mathrm{GH}$ plays a role in platelet production and differentiation. $\mathrm{GH}$ contributes to the regulation of erythropoiesis by increasing renal erythropoietin (EPO) production. It has been shown that erythropoiesis is slowed down due to GHD in hypophysectomized rats, recombinant $\mathrm{GH}$ treatment leads to an increase in EPO and stimulation of erythropoiesis, and GH increases IGF-1, which directly and indirectly stimulates erythropoiesis. ${ }^{4,6}$

There are few studies on the effect of long-term GH therapy on hematological parameters. This study aimed to investigate the changes in auxological and hematological parameters of patients who received GHT for IGHD.

\section{MATERIALS and METHODS}

\section{Study Design}

In this retrospective cross-sectional study, STROBE guideline was used for reporting purposes. ${ }^{7}$ The study protocol was approved by the Local Ethics Committee at University of Health Sciences Turkey, Erzurum Regional Training and Research Hospital (IRB number: 2019/07-60, date: 15.04.2019).

\section{Setting and Participants}

The study was conducted in the Pediatric Endocrinology outpatient clinics between May 2013 and May 2019.

Out of the 187 patients, who presented with short stature to the center during the study period, 62 patients with IGHD, who received recombinant $\mathrm{GH}$ treatment for at least two years and attended regular follow-up visits, were included in the study. The exclusion criteria of the study were the presence of other endocrine or chronic diseases $(n=1)$, receiving therapy with B12 or iron for anemia $(n=2)$, and use of non-GH therapeutics with potential effects on hematological parameters $(n=1)$ (Figure 1 ).

The IGHD is defined as a condition of GHD not associated with any organic lesion and also other pituitary hormone deficiencies. ${ }^{8}$

\section{Variables}

The demographic and clinical data were obtained from patient files such as age, sex, height and weight of the patients. The primary outcome of the study was set as the blood hemoglobin $(\mathrm{Hb})$ level. Other variables investigated were the age, gender, height at the time of diagnosis, weight, standard deviation scores (SDS), annual growth rate after $\mathrm{GH}$ treatment, white blood cell count (WBC), total lymphocyte count (LYM), absolute neutrophil count (NEU),

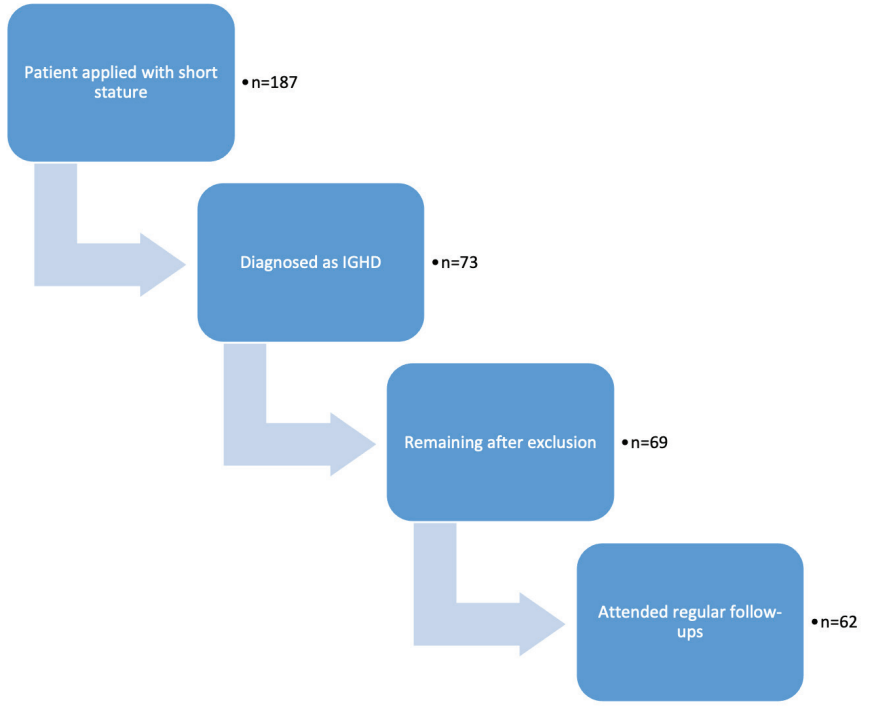

Figure 1. Participant flow diagram

IGHD: Isolated growth hormone deficiency

hematocrit (HCT), erythrocyte count (RBC), erythrocyte red cell distribution width (RDW), erythrocyte mean corpuscular volume (MCV), platelet count (PLT), mean platelet volume (MPV), and IGF1 levels. The hematological parameters included in the complete blood count were measured via a Sysmex XN-1000 device (Sysmex Ltd, Turkey) using the WNR, WDF, RET, DCL, SLS, and PLT kits.

Anthropometric measurements were performed using a calibrated device (Seca, 216, Hamburg, Germany) that measured weight and height in \pm 100 gram and $\pm 0.1 \mathrm{~cm}$ sensitivity SDs. Growth charts for Turkish children prepared by Neyzi et al. ${ }^{9}$ were used to evaluate height, weight, and SDS.

The patients were subcutaneously administered with 0.025-0.035 $\mathrm{mg} / \mathrm{kg} /$ day recombinant biosynthetic GHT in the evenings. ${ }^{10}$ The values obtained at the onset of the therapy were compared with those in the $6^{\text {th }}, 12^{\text {th }}, 18^{\text {th }}$, and $24^{\text {th }}$ months after the start of the GHT.

\section{Study Size}

The sample size was calculated based on the primary outcome, $\mathrm{Hb}$ level, using the GPower program. ${ }^{11}$ Considering the effect size as 0.15 (small), $\alpha$ error as 0.05 , power as $85 \%$, the number of groups as 1 , the number of repeated measurements as 5 , correlations among repeated measures as 0.5 , and non-sphericity correction as 1 , a total of 61 participants were determined for inclusion in the study group.

\section{Statistical Analysis}

Data were analyzed using the Statistical Package for the Social Sciences (SPSS) (SPSS for Windows, Version 20.0, Chicago, IC, USA). Results were presented as mean, SD, median, minimum, maximum, percentage, and numbers. The normal distribution of continuous variables was examined with the Shapiro-Wilk test. When the normal distribution could not be met for some 
variables, the Friedman test was used to compare more than two dependent group variables. The threshold for statistical significance was accepted as $p<0.05$.

\section{RESULTS}

Of the 62 patients included in the study, $37 \%(n=23)$ were female and $63 \%(n=39)$ were male. The age at the time of diagnosis ranged between 2 and 16 years, with a median of 10.8 years (9.9 for girls, 11.3 for boys).

The auxological and hematological parameters of all patients before and after GHT and the results of different gender groups are shown in Table 1, Table 2, and Table 3.

\section{DISCUSSION}

Our study showed that there were significant changes in some of the hematological parameters of patients with idiopathic GHD after two years of GHT and follow-up compared to the baseline. It is known that the GH/IGF-1 axis has a role in the regulation of hematopoiesis. The facts that erythropoiesis is impaired in adults with $\mathrm{GHD}$, and $\mathrm{Hb}$ and hematopoietic precursor cells increase after the GHT also support this relationship. ${ }^{12,13}$

It was found that the mean $\mathrm{Hb}$ values of the patients in our study increased significantly after the treatment compared to the baseline. Kawa et al. ${ }^{14}$ compared the hematological parameters of patients receiving GHT at baseline and in the $3^{\text {rd }}$ and $6^{\text {th }}$ months

Table 1. Comparison of the repeated measurements in all patients $(n=62)$

\begin{tabular}{|c|c|c|c|c|c|c|}
\hline & $\begin{array}{l}\text { Baseline } \\
\text { Mean } \pm \text { SD }\end{array}$ & $\begin{array}{l}6^{\text {th }} \text { month } \\
\text { Mean } \pm \text { SD }\end{array}$ & $\begin{array}{l}12^{\text {th }} \text { month } \\
\text { Mean } \pm S D\end{array}$ & $\begin{array}{l}18^{\text {th }} \text { month } \\
\text { Mean } \pm \text { SD }\end{array}$ & $\begin{array}{l}24^{\text {th }} \text { month } \\
\text { Mean } \pm \text { SD }\end{array}$ & $p$ \\
\hline Height SDS & $-2.96 \pm 1.03$ & $-2.66 \pm 1.07$ & $-2.43 \pm 1.05$ & $-2.22 \pm 1.10$ & $-2.14 \pm 1.05$ & $<0.001$ \\
\hline $\mathrm{Hb}(\mathrm{g} / \mathrm{dL})$ & $13.74 \pm 1.18$ & $13.89 \pm 1.07$ & $13.96 \pm 1.19$ & $14.61 \pm 3.65$ & $14.17 \pm 1.21$ & $<0.001$ \\
\hline HCT (\%) & $41.00 \pm 3.30$ & $42.01 \pm 3.26$ & $42.25 \pm 3.30$ & $42.04 \pm 4.76$ & $42.32 \pm 3.14$ & 0.006 \\
\hline RDW (\%) & $12.54 \pm 1.54$ & $12.18 \pm 1.03$ & $12.20 \pm 1.12$ & $12.50 \pm 1.14$ & $12.70 \pm 1.10$ & 0.005 \\
\hline $\operatorname{PLT}\left(10^{9} / \mathrm{L}\right)$ & $319.48 \pm 84.93$ & $344.05 \pm 97.94$ & $333.24 \pm 88.49$ & $323.15 \pm 71.95$ & $317.52 \pm 74.03$ & 0.001 \\
\hline MPV (fL) & $7.42 \pm 1.75$ & $7.69 \pm 1.98$ & $8.29 \pm 1.96$ & $9.58 \pm 7.38$ & $8.94 \pm 1.74$ & $<0.001$ \\
\hline WBC $\left(10^{9} / L\right)$ & $9.02 \pm 3.25$ & $8.57 \pm 2.30$ & $8.22 \pm 3.14$ & $7.94 \pm 2.50$ & $7.46 \pm 1.85$ & $<0.001$ \\
\hline
\end{tabular}

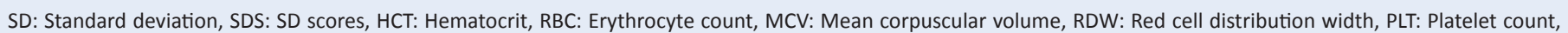
MPV: Mean platelet volume, WBC: White blood cell, LYM: Lymphocyte count, NEU: Neutrophil count

Table 2. Comparison of the repeated measurements in males $(n=39)$

\begin{tabular}{|c|c|c|c|c|c|c|}
\hline & $\begin{array}{l}\text { Baseline } \\
\text { Mean } \pm \text { SD }\end{array}$ & $\begin{array}{l}6^{\text {th }} \text { month } \\
\text { Mean } \pm S D\end{array}$ & $\begin{array}{l}12^{\text {th }} \text { month } \\
\text { Mean } \pm S D\end{array}$ & $\begin{array}{l}18^{\text {th }} \text { month } \\
\text { Mean } \pm \text { SD }\end{array}$ & $\begin{array}{l}24^{\text {th }} \text { month } \\
\text { Mean } \pm \text { SD }\end{array}$ & $p$ \\
\hline Height SDS & $-2.93 \pm 1.1$ & $-2.61 \pm 1.11$ & $-2.37 \pm 1.05$ & $-2.19 \pm 1.09$ & $-2.13 \pm 1.03$ & $<0.001$ \\
\hline $\mathrm{Hb}(\mathrm{g} / \mathrm{dL})$ & $13.71 \pm 1.11$ & $13.85 \pm 1.11$ & $14 \pm 1.26$ & $14.24 \pm 1.12$ & $14.35 \pm 1.2$ & $<0.001$ \\
\hline HCT (\%) & $40.96 \pm 3.28$ & $41.94 \pm 3.36$ & $42.71 \pm 3.54$ & $42.85 \pm 3.15$ & $43.02 \pm 3.17$ & $<0.001$ \\
\hline RDW (\%) & $12.63 \pm 1.61$ & $12.32 \pm 1.13$ & $12.33 \pm 1.1$ & $12.66 \pm 1.23$ & $12.69 \pm 1.11$ & 0.171 \\
\hline PLT $\left(10^{9} / \mathrm{L}\right)$ & $297.87 \pm 84.66$ & $326.43 \pm 97.67$ & $321.25 \pm 95.26$ & $310.02 \pm 69.57$ & $297.07 \pm 70.33$ & 0.001 \\
\hline MPV (fL) & $7.72 \pm 1.71$ & $7.99 \pm 1.9$ & $8.3 \pm 1.92$ & $8.61 \pm 1.82$ & $9.03 \pm 1.75$ & 0.262 \\
\hline WBC $\left(10^{9} / \mathrm{L}\right)$ & $9.08 \pm 3.43$ & $8.74 \pm 2.47$ & $8.27 \pm 3.36$ & $8.04 \pm 2.55$ & $7.2 \pm 1.45$ & $<0.001$ \\
\hline
\end{tabular}

SD: Standard deviation, SDS: SD scores, HCT: Hematocrit, RBC: Erythrocyte count, MCV: Mean corpuscular volume, RDW: Red cell distribution width, PLT: Platelet count, MPV: Mean platelet volume, WBC: White blood cell, LYM: Lymphocyte count, NEU: Neutrophil count 


\begin{tabular}{|c|c|c|c|c|c|c|}
\hline & $\begin{array}{l}\text { Baseline } \\
\text { Mean } \pm \text { SD }\end{array}$ & $\begin{array}{l}6^{\text {th }} \text { month } \\
\text { Mean } \pm \text { SD }\end{array}$ & $\begin{array}{l}12^{\text {th }} \text { month } \\
\text { Mean } \pm \text { SD }\end{array}$ & $\begin{array}{l}18^{\text {th }} \text { month } \\
\text { Mean } \pm \text { SD }\end{array}$ & $\begin{array}{l}24^{\text {th }} \text { month } \\
\text { Mean } \pm \text { SD }\end{array}$ & $p$ \\
\hline Weight SDS & $-1.89 \pm 1.37$ & $-1.95 \pm 1.29$ & $-1.79 \pm 1.37$ & $-1.67 \pm 1.34$ & $-1.6 \pm 1.34$ & 0.130 \\
\hline $\mathrm{Hb}(\mathrm{g} / \mathrm{dL})$ & $13.78 \pm 1.3$ & $13.94 \pm 1.02$ & $13.89 \pm 1.08$ & $15.23 \pm 5.83$ & $13.85 \pm 1.18$ & 0.572 \\
\hline $\mathrm{HCT}(\%)$ & $41.07 \pm 3.38$ & $42.13 \pm 3.15$ & $41.46 \pm 2.74$ & $40.66 \pm 6.52$ & $41.12 \pm 2.76$ & 0.254 \\
\hline MCV (fL) & $80.82 \pm 4.15$ & $82.52 \pm 3.59$ & $81.92 \pm 3.74$ & $82.13 \pm 3.54$ & $81.4 \pm 3.92$ & 0.157 \\
\hline RDW (\%) & $12.38 \pm 1.42$ & $11.92 \pm 0.76$ & $11.96 \pm 1.12$ & $12.22 \pm 0.92$ & $12.7 \pm 1.08$ & 0.028 \\
\hline PLT $\left(10^{9} / \mathrm{L}\right)$ & $356.13 \pm 73.41$ & $373.91 \pm 92.93$ & $353.56 \pm 73.12$ & $345.39 \pm 71.9$ & $352.17 \pm 68.24$ & 0.670 \\
\hline MPV (fL) & $6.9 \pm 1.71$ & $7.16 \pm 2.03$ & $8.27 \pm 2.06$ & $11.2 \pm 11.86$ & $8.79 \pm 1.75$ & $<0.001$ \\
\hline
\end{tabular}

of treatment and showed that GHT increased the erythroid cell line. Bergamaschi et al. ${ }^{15}$ found that GHT improved normochromic normocytic anemia in prepubertal children and patients receiving GHT in adulthood. Miniero et al. ${ }^{16}$ emphasized that among patients with idiopathic GHD, those with anemia before the GHT had a significant increase in $\mathrm{Hb}$-SDS after 12 months of GHT, and normal $\mathrm{Hb}$ values were achieved in all of the children. It has also been mentioned that GH and IGF-1 directly modulate hematopoiesis through their proliferative and anti-apoptotic effects and indirectly through regulating cytokine production. ${ }^{17}$ Considering these studies together, the effect of $\mathrm{GH}$ on hematopoiesis is obvious, but its role in hematopoiesis and the mechanisms that keep the balance are still not clear.

It was found that the mean HCT and RBC of the patients in our study increased significantly after the GHT compared to the baseline. In a study by Esposito et al. ${ }^{18} 12$ patients with GHD were diagnosed as having normocytic anemia, and $\mathrm{Hb}, \mathrm{HCT}$, and RBC of these patients were found to increase in the first two years of GHT. They also showed that the anemia improved in all of these patients in the $5^{\text {th }}$ year of their treatment. In our study, 2 patients were found to have anemia before the GHT, and their anemia improved after 2 years of treatment, with a significant increase in RBC counts. Pankratova et al. ${ }^{19}$ emphasized that the RBC counts were lower in children with GHD before treatment, which increased after 12 months of GHT.

The GHT indirectly increases $\mathrm{Hb}$ by increasing EPO production in the kidneys in the early period and by enhancing the effect of EPO at the receptor level. In addition, IGF-1 stimulates the maturation and proliferation of erythroid cell lines with an EPO-like effect by acting on its own receptors expressed on erythroid precursors. $\mathrm{GH}$ stimulates the production of IGF-1 by inducing the hematopoietic progenitor cells, and the increased IGF-1 stimulates erythropoiesis by inducing autocrine and paracrine effects in the hematopoietic system. ${ }^{14,15,20,21}$ One of the limitations of our study was that it was done retrospectively; therefore, the EPO levels could not be measured, and no data could be obtained to evaluate this relationship. The fact that there was an increase in $\mathrm{Hb}, \mathrm{HCT}, \mathrm{RBC}$, RDW, and MCV, which were among the parameters related to the erythroid cell line, after the GHT compared to the baseline supported the hypothesis that GHT stimulated erythropoiesis.

With regard to the platelet parameters, it was found that platelet values were not at levels that would be a risk factor for bleeding or thrombosis at the baseline or during the treatment, and the variations were not considered to be clinically significant. Xu et al. ${ }^{22}$ showed that GH positively affected platelet production and differentiation in vitro. Similar to our study, Esposito et al. ${ }^{18}$ did not detect a significant difference between the patient and control group in terms of PLTs before and after GHT. No effect of GHT has been shown on PLT in a small number of human studies.

In our study, it was found that the MPV increased significantly during the GHT compared to the baseline $(p<0.001)$. There is no study in the literature examining the relationship between MPV and GHT. It was found that, in adults with acromegaly (with excess GH), MPV was higher before treatment compared to the control group, and MPV decreased with the decrease in GH levels after the treatment. ${ }^{23,24}$ This finding is consistent with those of our study, which can be explained by the fact that GH increases platelet activation.

In our study, WBC, lymphocyte, and NEUs were significantly lower at baseline compared to those after the treatment. No previous study has been found about the effects of GHT on the WBC, lymphocyte, and neutrophil levels and their functions in children with GHD. In studies evaluating the hematological parameters, it was reported that $\mathrm{GH}$ had no effect on leukocyte count. ${ }^{14,18 \text {, }}$ ${ }^{21}$ Positive effects of GHT have been demonstrated in children with GHD and phagocytic dysfunction. ${ }^{25}$ It has been stated that treatments aimed at reducing $\mathrm{GH}$ in patients with acromegaly can reduce NEUs. However, a clear distinction could not be made regarding whether this is due to the decrease in $\mathrm{GH}$ levels or a drug-related side effect. ${ }^{26}$ 
In our study, WBC, lymphocyte, and NEUS were not below the limits in any of the patients at the baseline or during the 2-year treatment and follow-up, and the differences did not lead to any clinically significant change. The fact that our study did not evaluate the functions of erythrocytes, leukocytes, and thrombocytes, although the effect of GHT on the level of these cells was investigated, was a limitation of our study.

\section{CONCLUSION}

In conclusion, no significant hematological abnormality was detected before GHT in idiopathic GHD. GHT was found to have erythropoiesis stimulatory effects. In addition, it was shown that GHT was associated with some clinically insignificant changes on platelet, WBC, lymphocyte, NEUs and MPV. We think that in vitro and molecular studies to explain these effects of GHD and GHT may help clarify the subject matter.

\section{Ethics}

Ethics Committee Approval: The study protocol was approved by the Local Ethics Committee at University of Health Sciences Turkey, Erzurum Regional Training and Research Hospital (IRB number: 2019/07-60, date: 15.04.2019).

Informed Consent: Retrospective cross-sectional study.

Peer-reviewed: Externally and internally peer-reviewed.

\section{Authorship Contributions}

Concept: A.Ç., Design: A.Ç., Data Collection or Processing: D.Ş., Analysis or Interpretation: D.Ş., Literature Search: A.Ç., D.Ş., Writing: A.Ç., D.Ş.

Conflict of Interest: The authors declared no potential conflicts of interest with respect to the research, authorship, and/or publication of this article.

Funding: The authors received no financial support for the research, authorship, and/or publication of this article.

\section{REFERENCES}

1. Lindsay R, Feldkamp M, Harris D, Robertson J, Rallison M. Utah growth study: growth standards and the prevalence of growth hormone deficiency. J Pediatr. 1994;125:29-35.

2. Stanley T. Diagnosis of growth hormone deficiency in childhood. Curr Opin Endocrinol Diabetes Obes. 2012;19:47-52.

3. Bianchi A, Giampietro A, Pontecorvi A, De Marinis L. Isolated growth hormone deficiency: clinical entity? J Endocrinol Invest. 2008;31(9 Suppl 9):12-5.

4. Jørgensen AP, Fougnnger KJ, Ueland T, et al. Favorable long-term effects of growth hormone replacement therapy on quality of life, bone metabolism, body composition and lipid levels in patients with adult-onset growth hormone deficiency. Growth Horm IGF Res. 2011;21:69-75.

5. Follin C, Thilén U, Osterberg K, Björk JK, Erfurth EM. Cardiovascular risk, cardiac function, physical activity, and quality of life with and without long-term growth hormone therapy in adult survivors of childhood acute lymphoblastic leukemia. J Clin Endocrinol Metab. 2010;95:3726-35.

6. Kurtz A, Zapf J, Eckardt KU, et al. Insulin-like growth factor I stimulates erythropoiesis in hypophysectomized rats. Proc Natl Acad Sci U S A. 1988;85:7825-9.
7. von Elm E, Altman DG, Egger M, et al. The strengthening the reporting of observational studies in epidemiology (STROBE) statement: guildelines for reporting observational studies. J Clin Epidemiol. 2008;61:344-9.

8. Hernández LM, Lee PDK, Camacho-Hübner C. Isolated growth hormone deficiency. Pituitary. 2007;10:351-7.

9. Neyzi O, Bundak R, Gökçay G, et al. Reference values for weight, height, head circumference, and body mass index in Turkish Cchildren. J Clin Res Pediatr Endocrinol. 2015;7:280-93.

10. Ranke MB. Pediatric growth hormone deficiency (GHD) in the recombinant human GH (rhGH) Eera. Pediatr Endocrinol Rev. 2018;16 (Suppl 1):63-9.

11. Lenth R. Java Applets for Power and Sample Size [Computer software]. Russ Lenth - Department of Statistics and Actuarial Science - University of lowa, 2009.

12. Eugster EA, Fisch M, Walvoord EC, DiMeglio LA, Pescovitz OH. Low hemoglobin levels in children with in idiopathic growth hormone deficiency. Endocrine. 2002;18:135-6.

13. Vihervuori E, Sipilä I, Siimes MA. Increases in hemoglobin concentration and iron needs in response to growth hormone treatment. J Pediatr. 1994;125:242-5.

14. Kawa MP, Stecewicz I, Piecyk K, et al. The impact of growth hormone therapy on the apoptosis assessment in CD34+ hematopoietic cells from children with growth hormone deficiency. Int J Mol Sci. 2017;18:111.

15. Bergamaschi S, Giavoli C, Ferrante E, et al. Growth hormone replacement therapy in growth hormone deficient children and adults: effects on hemochrome. J Endocrinol Invest. 2006;29:399-404.

16. Miniero $\mathrm{R}$, Altomare $\mathrm{F}$, Rubino $\mathrm{M}$, et al. Effect of recombinant human growth hormone (rhGH) on hemoglobin concentration in children with idiopathic growth hormone deficiency-related anemia. J Pediatr Hematol Oncol. 2012;34:407-11.

17. Hanley MB, Napolitano LA, McCune JM. Growth hormone-induced stimulation of multilineage human hematopoiesis. Stem Cells. 2005;23:1170-9.

18. Esposito A, Capalbo D, De Martino L, et al. Long-term effects of growth hormone $(\mathrm{GH})$ replacement therapy on hematopoiesis in a large cohort of children with GH deficiency. Endocrine. 2016;53:192-8.

19. Pankratova $M$, Yusipovich $A$, Vorontsova $M$, et al. One-year recombinant growth hormone therapy does not improve hemoglobin state and morphology of erythrocytes in growth hormone deficient children. Pathophysiology. 2018;25:13-17.

20. Sohmiya M, Kanazawa I, Kato Y. Effect of recombinant human GH on circulating granulocyte colony-stimulating factor and neutrophils in patients with adult GH deficiency. Eur J Endocrinol. 2005;152:211-5.

21. Meazza C, Bonomelli I, Pagani S, et al. Effect of human recombinant growth hormone therapy on circulating levels of erythropoietin and granulocytecolony stimulating factor in short children. J Pediatr Endocrinol Metab. 2009;22:837-43.

22. Xu Y, Wang S, Shen M, et al. hGH promotes megakaryocyte differentiation and exerts a complementary effect with c-Mpl ligands on thrombopoiesis. Blood. 2014;123:2250-60.

23. Demirpence M, Yasar HY, Colak A, et al. Mean platelet volume and platelet function analysis in acromegalic patients before and after treatment. Acta Endocrinol (Buchar). 2016;12:401-6.

24. Unüubol M, Güuney $E$, Tüure $M$, Eryıilmaz U. Mean platelet volume and arterial stiffness in patients with acromegaly. Anatol J CardiolAnadolu Kardiyoloji Derg. 2014;14:456-63.

25. Kotzmann $H$, Riedl $M$, Clodi $M$, et al. The influence of growth hormone substitution therapy on erythroid and myeloid progenitor cells and on peripheral blood cells in adult patients with growth hormone deficiency. Eur J Clin Invest. 1996;26:1175-81.

26. Manfredi R, Tumietto F, Azzaroli L, et al. Growth hormone (GH) and the immune system: impaired phagocytic function in children with idiopathic $\mathrm{GH}$ deficiency is corrected by treatment with biosynthetic $\mathrm{GH}$. J Pediatr Endocrinol. 1994;7:245-51. 